\title{
IDENTIDADES SOCIAIS, PADRONIZAÇÃO E CORES: A TRAJETÓRIA DE LENINA EM ADMIRÁVEL MUNDO NOVO, DE ALDOUS HUXLEY
}

\begin{abstract}
Alana Michelli Bof ${ }^{1}$
Roberto Rossi Menegotto ${ }^{2}$

Resumo: Em Admirável mundo novo, romance distópico do inglês Aldous Huxley, as diferentes castas em que a sociedade é divida trajam roupas com cores que demarcam as suas posições sociais. No entanto, a personagem Lenina Crowne, pertencente ao grupo Beta, veste diferentes colorações ao longo da narrativa, contrariando os processos de controle mental aos quais foi submetida. Desse modo, o objetivo deste artigo é investigar a trajetória de Lenina, observando como, apesar de ter passado por diferentes processos de condicionamento, as cores de seu vestuário podem representar a sua sobreposição à normatização das identidades sociais. O amparo bibliográfico é oriundo de autores como Eva Heller (2013), Jean Chevalier e Alain Gheerbrant (2017), Kathryn Woodward (2000), Pierre Bourdieu (1989) e Stuart Hall (2000; 2015).

Palavras-chave: Admirável mundo novo; Lenina; Identidade social; Cores.

Abstract: In Brave new world, a dystopian novel by Aldous Huxley, the different castes, in which the society is divided, are identified by the color of their clothing. However, Lenina Crowne, a member of the Beta group, wear pieces of clothing in different colors over the course of the narrative, contradicting the mental control processes in which she was submitted. Therefore, the objective of this article is to investigate Lenina's characterization, in which, even though going through multiple conditioning processes, the coloring of her clothing might represent an overlapping of the social identities's streamlining. Our sources consist of authors such as Eva Heller (2013), Jean Chevalier and Alain Gheerbrant (2017), Kathryn Woodward (2000), Pierre Bourdieu (1989) and Stuart Hall (2000; 2015).
\end{abstract}

Keywords: Brave new world; Lenina; Social identities; Colors.

1 Pós-graduanda em Influência Digital - Conteúdo e Estratégia, pela Pontifícia Universidade Católica do Rio Grande do Sul (PUCRS). E-mail: lanamichelli@hotmail.com

2 Bolsista PROSUC/CAPES no Programa de Doutorado em Letras - Associação Ampla UCS/UniRitter. Mestre em Letras, Cultura e Regionalidade pela Universidade de Caxias do Sul. E-mail: roberto.rmenegotto@gmail.com 


\section{INTRODUÇÃO}

Mais do que uma sociedade futurista fruto da imaginação do britânico Aldous Huxley (1894-1963), Admirável mundo novo, publicado em 1932, apresenta críticas sociais incrustadas em sua narrativa. Na obra, considerada uma das principais de literatura distópica, percebe-se a característica elementar dessa temática: atentar para os rumos tomados pela sociedade, destacando consequências extremas de suas decisões, do presente para o futuro. Segundo Leomir Cardoso Hilário:

O romance distópico pode então ser compreendido enquanto aviso de incêndio, o qual, como todo recurso de emergência, busca chamar a atenção para que o acontecimento perigoso seja controlado, e seus efeitos, embora já em curso, sejam inibidos (HILÁRIO, 2013, p. 202).

Entretanto, no enredo de Admirável mundo novo, há uma particularidade, quando comparado ao de outras obras que figuram como grandes romances distópicos do século XX, como 1984, de George Orwell, Laranja mecânica, de Anthony Burgess, e Farenheit 451, de Ray Brasbury. Nos livros supracitados, a sátira da sociedade parte de um ponto de vista negativo, em que as condições de vida da população são, majoritariamente, precárias. No caso de 1984 há, além do controle excessivo por parte do governo, a escassez de recursos básicos, como comida, e a precariedade em termos de infraestrutura; em Laranja mecânica, o grande problema são os níveis extremos de violência praticada pelos jovens; enquanto, em Farenheit 451, a perspectiva recai sobre a falta de propósito e de consciência das pessoas, com livros proibidos e entretenimento barato que tentam, além de controlar, alienar quanto à infelicidade geral.

Por outro lado, em Admirável mundo novo, a sociedade em questão, que integra o chamado Estado Mundial, beira a perfeição: a maior parte dos indivíduos ${ }^{3}$ vive confortavelmente dentro de classes sociais escolhidas previamente ao nascimento; há prosperidade tecnológica, todos os ambientes são higienizados, há abundância de bens materiais para atender aos desejos de consumo da população e guerras e doenças foram, praticamente, erradicadas. Além disso, caso sentimentos negativos - e, portanto, indesejados - despertem, pequenas doses do medicamento "Soma" podem controlá-los. As palavras de ordem, impostas pelo Estado Mundial, e que compõem o seu lema, são: comunidade, estabilidade e identidade. Esses fatores fazem Admirável mundo novo assemelhar-se ao romance considerado o precursor das distopias modernas: Nós, escrito pelo russo Ieguêni Zamiátin, em 19244.

A característica que faz a obra de Aldous Huxley figurar entre as literaturas distópicas é o alijamento da individualidade e da liberdade nas escolhas dos cidadãos. Isso porque, sob

3 Utilizaremos "indivíduo(s)" para nos referirmos a "pessoa(s)", de modo geral. Porque, como veremos, em romances distópicos, os governos autoritários visam a reduzir ao máximo as possibilidades de individualidades dos sujeitos.

4 A história do livro é marcada por um governo totalitário, chamado Estado Único, extremamente manipulador, que faz com que a população aprecie o sistema adotado. O controle, em todas as áreas, é tamanho, que o livre-arbítrio é um conceito ultrapassado: tudo é regido pela lógica e pela mecanização. A obra também é marcada pela perda das identidades individuais a ponto de as pessoas não terem mais nomes, mas, sim, números. 
o governo do Estado Mundial, as pessoas são produzidas em proveta, em escala industrial. Milhares de embriões são cultivados simultaneamente, em grandes laboratórios-fábricas que compõem os chamados Centro de Incubação e Condicionamento, em que o produto final é o próprio ser humano. Essas pessoas fabricadas são condicionadas, desde a fase embrionária, por meio do controle genético, a possuírem, ou não, determinadas habilidades e faculdades. Desse modo, conforme as suas pré-designações biológicas, são alocadas em uma das cinco castas que compõem aquela sociedade: Alfa, Beta, Gama, Delta ou Ípsilon. A total submissão é completada por técnicas de condicionamento aplicadas, desde a infância, para determinar a orientação do pensamento e as preferências dos indivíduos. Como explica Theodor Adorno:

O ponto de partida parece ser a percepção da semelhança universal de tudo o que é produzido em massa, sejam coisas ou homens. A metáfora schopenhaueriana da manufatura da natureza é tomada ao pé da letra. Fervilhantes exércitos de gêmeos são preparados nas retortas, um pesadelo de sósias infinitos, como o pesadelo diurno que irrompe no cotidiano com a fase recente do capitalismo, o pesadelo dos sorrisos normatizados, da graça fornecida pela charm school, da consciência standardizada das multidões que seguem as trilhas ditadas pela communication industry (ADORNO, 2001, p. 92).

O processo de controle biológico que leva a uma produção massiva de seres humanos com comportamentos normatizados também resulta na formação de identidades que não são construídas ao longo do tempo, mas, sim, fabricadas, substituindo a individualidade pela coletividade. Segundo Stuart Hall (2004), a nossa sociedade oscila entre processos que visam a fixar as identidades e outros que buscam desestabilizá-las. No caso do modelo social criado por Huxley (2014), os movimentos de subversão, que balançam os alicerces identitários, já, quase, não existem mais, pois, como se verifica no lema do Estado Mundial, há uma busca pela estabilidade total. Portanto, a produção/construção de identidades estáveis manifesta-se no contexto social, com efeitos pré-estabelecidos e controlados. Como explica Denys Cuche, sobre o sistema identitário no mundo "real":

A construção da identidade se faz no interior de contextos sociais que determinam a posição dos agentes e por isso mesmo orientam suas representações e suas escolhas. Além disso, a construção da identidade não é uma ilusão, pois é dotada de eficácia social, produzindo efeitos sociais reais (CUCHE, 1999, p. 182).

Na obra, a caracterização das castas, feita pelo Estado Mundial, é determinante para a concepção dos indivíduos e para o estabelecimento de suas identidades, atribuindo valores e estabelecendo uma categorização social. Conforme Hall, "dividir e classificar significa, neste caso, também hierarquizar. Deter o privilégio de classificar significa também deter o privilégio de atribuir diferentes valores aos grupos assim classificados" (2004, p. 82). Percebe-se, então, que essa lógica também se aplica à sociedade criada por Huxley (2014). 
Em Admirável mundo novo, a pirâmide social é composta por duas classes superiores, dotadas de maior inteligência e que ocupam cargos de importância elevada: Alfa, que está no topo, e Beta, logo abaixo. As três classes inferiores, em ordem decrescente de importância, são Gama, Delta e Ípsilon. Os membros desses três grupos, durante o seu processo de fabricação, passam pelo chamado processo bokanovski: o embrião é manipulado para se dividir dezenas de vezes, resultando em uma grande quantidade de gêmeos idênticos. $\mathrm{O}$ processo "consiste essencialmente numa série de paradas do desenvolvimento. Nós detemos o crescimento normal e, paradoxalmente, o ovo reage germinando em múltiplos brotos" (HUXLEY, 2014, p.12). Consequentemente, esses indivíduos têm o cérebro menos desenvolvido e ocupam funções repetitivas e que não exigem habilidades lógicas e de pensamento.

$\mathrm{Na}$ narrativa, as pessoas são compelidas a vestirem roupas de uma cor que demarque a casta à qual pertencem, assim, atribuindo mais ou menos valor a cada indivíduo. Os Alfas utilizam o cinza; entre os Betas, predomina o violeta, para os Gamas, é determinado o verde; os Deltas são caracterizados pelo cáqui; e os Ípsilons vestem-se de preto. Nos processos de condicionamento moral, como é caso da hipnopédia ${ }^{5}$, a cor é constantemente referida para que a ordem social entre as castas seja enfatizada, como pode-se observar no excerto a seguir, em que crianças Betas são submetidas ao processo hipnopédico:

As crianças Alfas estão todas vestidas de cinza. Elas trabalham muito mais que nós porque são formidavelmente inteligentes. De fato estou muito contente por ser um Beta, pois não trabalho tanto. E depois, somos muito superiores aos Gamas e aos Deltas. Os Gamas são patetas. Estão todos vestidos de verde e as crianças Deltas estão vestidas de caqui. Oh, não, não quero brincar com as crianças Deltas (HUXLEY, 2014, p. 25).

A atribuição de valor social a cada cor é, portanto, ensinada e reforçada desde a infância. Tanto em nossa sociedade, quanto na obra, as cores carregam significados que a elas são atribuídos culturalmente. Para Modesto Farina (1990, p. 27), "na realidade, a cor é uma sintaxe individual. O homem reage a ela subordinado às suas condições físicas e às suas influências culturais. Não obstante, ela possui uma sintaxe que pode ser transmitida, ensinada." Desse modo, a utilização de cores como demarcadores de posição social enfatiza a homogeneização de identidades dentro de cada casta. Chevalier e Gheerbrant (1999) afirmam que:

O primeiro caráter do simbolismo das cores é a sua universalidade, não só geográfica mas também em todos os níveis do ser e do conhecimento, cosmológico, psicológico, místico etc. As interpretações podem variar. [...] As cores permanecem, no entanto, sempre e sobretudo como fundamentos do pensamento simbólico (CHEVALIER; GHEERBRANT, 1999, p. 275).

5 Consiste no ensino de preceitos morais durante o sono, por meio de gravações de áudio que são repetidas dezenas de vezes. 
Apesar desse contexto, uma das personagens da história mostra, de maneira sutil, uma tendência de contrariar o sistema simbólico vigente. Lenina Crowne, enfermeira de um dos laboratórios do Centro de Incubação, pertence à classe dos Betas ${ }^{6}$ e, embora o violeta seja a cor distintiva de sua casta, ela utiliza outras colorações no decorrer do enredo. Portanto, o objetivo deste artigo é investigar a trajetória de Lenina, observando como, apesar de ter passado por diferentes processos de condicionamento, as cores de seu vestuário podem representar a sua sobreposição à normatização das identidades sociais.

\section{A INTERPRETAÇÃO DAS CORES NA IDENTIDADE DE LENINA}

Admirável mundo novo tem, entre seus protagonistas, Bernard Marx, funcionário do Departamento de Psicologia do Centro de Incubação localizado em Londres. Ele pertence à casta superior dos Alfas-Mais, porém, sofre discriminação devido à sua baixa estatura, algo incomum para os membros da linhagem. Segundo os rumores, "- Dizem que alguém se enganou quando ele ainda estava no bocal. Pensaram que fosse um Gama e puseram álcool no seu pseudossangue" (HUXLEY, 2014, p. 69).

Além da altura, Bernard diferencia-se dos demais por ter pensamentos questionadores acerca do modelo social proposto pelo Estado Mundial. Por vezes, suas dúvidas são externadas, porém, longe das autoridades: "o que sentiria eu se pudesse, se fosse livre, se não estivesse escravizado pelo meu condicionamento?” (HUXLEY, 2014, p. 117). Assim, pode-se inferir que, apesar de todas as técnicas para condicionamento e controle pelos quais passam os indivíduos dessa sociedade para que sejam perfeitamente estáveis e estejam satisfeitos com sua condição, uma pequena porcentagem, por razões que fogem ao controle dos governantes, diferencia-se dos demais e apresenta um certo grau de capacidade de reflexão.

No início do enredo, Bernard convida Lenina Crowne, sua colega de trabalho, para um encontro. Lenina, que sempre teve curiosidade de ver e conhecer os costumes dos povos habitantes do lado de fora das fronteiras consideradas civilizadas, aceita com facilidade o convite para visitar uma Reserva Selvagem, visto que a posição social e a profissão de Bernard permitem que eles obtenham acesso ao local. Antes de partirem, porém, são avisados para que tenham cuidado, pois, há muitos anos, em uma visita à Reserva, uma jovem Beta desapareceu. Na Reserva Selvagem, presenciam rituais próprios da cultura considerada incivilizada, e Lenina fica incomodada ao saber que, nesse lugar, a procriação é feita por meio de relações sexuais, método considerado ultrapassado e absurdo. No povoado, conhecem um selvagem chamado John, diferente dos demais, por suas características físicas, por seu vocabulário e conhecimentos acerca do mundo "civilizado". Ele e Lenina aproximam-se e sentem-se atraídos um pelo outro.

Em uma conversa, John revela que é filho da mulher Beta que havia desaparecido, cha-

\footnotetext{
6 A casta de Lenina não é diretamente mencionada na obra, mas pode-se inferir que ela é uma Beta. A personagem tem uma profissão em que exerce um "trabalho manual", apesar de sua grande inteligência. Além disso, não pertence às castas inferiores, pois demonstra satisfação por não ser uma Gama. Ela também não é uma Alfa, visto que as pessoas dessa casta ocupam altos postos, como funções administrativas e de gestão.
} 
mada Linda. Como ele tem uma grande curiosidade de conhecer o admirável mundo novo ${ }^{7}$, tantas vezes descrito por sua mãe, e a própria Linda anseia por retornar para casa, decidem retornar a Londres com Bernard e Lenina.

Apelidado de "Selvagem", John torna-se uma grande atração para os londrinos, que pouco sabem sobre os não-civilizados. Conforme ele conhece as normas e o modelo determinados pelo Estado Mundial, desilude-se, pois não concorda com os hábitos dessa nova cultura. O ápice de seu descontentamento ocorre quando Lenina, apaixonada, tenta seduzi-lo. John considera o ato um absurdo, pois, em sua cultura, o homem deve passar por provações para conquistar uma mulher.

Em seguida, ele vai até o Hospital de Park Lane visitar sua mãe que está prestes a morrer. Quando está saindo do local, John observa os Deltas que trabalham lá e, em uma explosão de raiva, grita para a multidão que o Soma que está sendo distribuído é um veneno que os aprisiona, e atira doses da droga pela janela. Bernard, que acompanhava o Selvagem na ocasião da visita a Linda, acaba sendo preso junto com ele. Após, ambos são convocados para uma reunião com o Administrador Mundial, que toma uma decisão: exila Bernard em uma ilha, pois é para lá que vão as pessoas demasiadamente conscientes:

Vai ser mandado para uma ilha, isto é, para um lugar onde conhecerá o mais interessante conjunto de homens e mulheres existentes em qualquer parte do mundo. Todas as pessoas que, por esta ou aquela razão, adquiriram demasiada consciência de sua individualidade para poderem adaptar-se à vida comunitária; todas as pessoas a quem a ortodoxia não satisfaz, que têm ideias próprias e independentes; todos aqueles, numa palavra, que são alguém (HUXLEY, 2014, p. 272).

John, chocado com os últimos acontecimentos, decide fugir e isolar-se em uma montanha, onde pretende cultivar os costumes da Reserva Selvagem em que nasceu. Com o tempo, o seu esconderijo é descoberto e se torna uma atração turística. Diversas pessoas visitam o local para ver o famoso Selvagem exercendo práticas primitivas, atormentando-o.

A narrativa encerra-se com a morte de John, que comete suicídio, após Lenina visitá-lo. Seu corpo é encontrado pendurado pelo pescoço dentro da casa onde morava, na montanha.

Em uma leitura mais superficial da obra de Huxley, é possível considerar Lenina uma figura secundária, que não ocupa o protagonismo da história, quando comparada a outros personagens. No entanto, em uma análise verticalizada do enredo, pode-se inferir que ela tem considerável relevância, tanto como um elo entre os demais personagens, quanto por seu caráter transgressor. Lenina trabalha no Laboratório do Centro de Incubação e, no início da narrativa, está envolvida com Henry Foster, um jovem que exerce a função de Administrador de Incubação no mesmo prédio. Pouco tempo depois, ela inicia um relacionamento com Bernard Marx. Ele é mais consciente e crítico que Lenina, e questiona o modelo

$7 \mathrm{Na}$ Reserva Selvagem, John tem acesso a livros proibidos pelo Estado Mundial, pois podem distorcer o raciocínio e levar ao caos. Comumente, em seus diálogos, ele cita Shakespeare. Admirável mundo novo é uma alusão direta ao Ato V da peça A tempestade: "MIRANDA — Oh! Que milagre! Que soberbas criaturas aqui vieram! Como os homens são belos! Admirável mundo novo que tem tais habitantes" (SHAKESPEARE, 1996, p. 57)! 
sócio-cultural em que está inserido. Ainda assim, apesar da "normalidade” de Lenina, algumas atitudes e, principalmente, símbolos ligados a ela demonstram a busca da personagem por uma identidade diferenciada daquela que lhe foi imposta.

Inicialmente, pode-se observar que os relacionamentos íntimos da personagem não seguem a conformidade. Lenina mostra-se incomodada com as imposições, feitas pelo Estado Mundial, para o envolvimento sexual. Visto que a preservação da espécie humana não depende mais do processo de reprodução natural, famílias não são mais constituídas. Os indivíduos são estimulados a terem relações poligâmicas desde a infância e os comportamentos diferenciados, como passar um longo período desacompanhado, ou o não-revezamento de parceiros, geram estranheza à população e às autoridades. Em uma conversa com sua colega, Fanny, Lenina revela que está saindo há quatro meses com Henry Foster, o que causa indignação na amiga:

- Mas afinal de contas - protestou Lenina - faz apenas quatro meses que ando com Henry.

- Apenas quatro meses! Essa é boa! E além disso, continuou Fanny, apontando-lhe um dedo acusador - não houve mais ninguém durante todo esse tempo, não é?

Lenina enrubesceu, mas seus olhos e o tom de sua voz continuaram desafiadores

- Não, não houve mais ninguém - respondeu, quase com truculência. - E, francamente, não vejo por que teria de haver alguém mais.

\section{$[\ldots]$}

- Mas falando sério, eu acho mesmo que você deveria se cuidar. É tão terrível continuar tanto tempo assim com um único homem. Aos quarenta anos, ou aos trinta e cinco, vá lá. Mas na sua idade, Lenina! Não, francamente isso não se faz. E você sabe como o D.I.C se opõe a tudo que for intenso ou muito prolongado (HUXLEY, 2014, p. 62).

Em outra circunstância, Lenina revela a Fanny que Bernard Marx convidou-a para sair e que ela irá visitar, na companhia dele, uma Reserva Selvagem, graças às credenciais de Bernard para adentrar aquele espaço. Esse interesse da personagem em conhecer uma sociedade diferente daquela com a qual está acostumada demonstra, mais uma vez, a tendência que ela tem de questionar regras e limites impostos.

Algumas particularidades simbólicas, também podem ser interpretadas como a vontade de Lenina de se libertar da normatização imposta, como as cores das roupas usadas pela personagem Para Durand (1995, p. 11-12, grifo original), “o símbolo é, como a alegoria, recondução do sensível, do figurado ao significado, mas é também, pela própria natureza 
do significado inacessível, epifania, isto é, aparição, através do e no significado, do indizível. [...] É, pois, uma representação que faz aparecer um sentido secreto, é a epifania de um mistério."

$\mathrm{Na}$ condição de membro da casta Beta, Lenina deve vestir-se com uma indumentária, predominantemente, da cor violeta. No entanto, na primeira menção à coloração do vestuário da jovem, o verde é ostentado:

- Estou bem assim? Perguntou Lenina. Sua blusa era de tecido de acetato verde-garrafa, com pele de viscose verde nos punhos e na gola.

Um short de veludo cotelê verde e meias brancas e lã de viscose, dobradas logo abaixo do joelho.

Um boné de jóquei verde e branco, protegia os olhos de Lenina; seus sapatos eram de um verde vivo e muito lustrosos.

\section{$[\ldots]$}

E na cintura ela trazia uma cartucheira verde de pseudomarroquim com detalhes em prata, que continha a provisão regulamentar de anticoncepcionais (HUXLEY, 2014, p.72).

Apesar do verde ser característico dos Gama, Lenina deixa claro que não tem qualquer identificação com a casta. Ao ver uma multidão de indivíduos vestindo verde e chegando para trabalhar em uma indústria, a personagem desdenha do grupo e repete uma das frases apreendidas durante os sonos hipnopédicos:: “- Palavra de honra - disse Lenina - estou contente de não ser uma Gama" (HUXLEY, 2014, p. 87). Portanto, o fato de ela optar pelo verde em lugar do violeta, ainda que de forma inconsciente, pode ser interpretado devido ao caráter simbólico de cada uma dessas colorações. Segundo Eva Heller (2013, p. 368) o violeta é visto, em algumas culturas, como a cor símbolo da humildade e do recato: “'Seja como a violeta nos campos, humilde, modesta e recatada'... Desde a antiguidade, as violetas eram a cor símbolo da moderação". Em diversos momentos da obra de Huxley, percebe-se que essas características não condizem com a personalidade de Lenina, como é possível perceber no excerto: "O elevador estava cheio de homens que vinham do vestiário dos Alfas, e a entrada de Lenina foi colhida com diversos acenos e sorrisos amistosos. A jovem era muito popular e, numa ou noutra ocasião, havia passado a noite com quase todos eles" (HUXLEY, 2014, p. 81).

Outro significado da cor, segundo Chevalier e Gheerbrant (2009) é a obediência e a submissão. Como já observado anteriormente, apesar de Lenina obedecer a muitos dos pre- 
ceitos aos quais foi condicionada, ela tem uma consciência difusa e apresenta alguns traços e vontades próprias, em desacordo com as regras vigentes. Além disso, os autores também destacam o fato de o violeta ser a cor imediatamente oposta ao verde no horizonte do círculo vital. Enquanto o violeta simboliza o outono, com a passagem da vida à morte, o verde representa o oposto, como a primavera: "seria, portanto, de certa forma, a outra face do verde e como ele estaria ligado ao simbolismo da goela ${ }^{8}$, sendo o violeta a goela que engole e apaga a luz enquanto o verde é a goela que reacende a luz" (CHEVALIER; GHEERBRANT, 2009, p. 960). Ademais, a ideia do violeta como oposição ao verde é corroborada por Heller (2013, p. 194): "a cor que, em termos psicológicos, mais contrasta com o verde é o antinatural, o artificial violeta."

Deste modo, é possível interpretar que a substituição do violeta pelo verde nas vestimentas de Lenina representa a sua busca por libertação, pela vida natural, e a refutação dos propósitos determinados pelo Estado Mundial. Inconscientemente, a personagem parece guardar traços de autenticidade e de não conformismo, a despeito de todas as técnicas de condicionamento às quais foi submetida. Em um diálogo entre Lenina e Bernard, o homem faz reflexões e expõe pensamentos contra-hegemônicos:

Ele começou a dizer-lhe uma porção de absurdos incompreensíveis e perigosos. Lenina fez o que pôde para tapar mentalmente os ouvidos, mas de vez em quando um fragmento insistia em se tornar perceptível..."para experimentar o efeito produzido pela repressão dos meus impulsos", ouviu-o dizer. Essas palavras pareceram despertar algo em seu espírito. (HUXLEY, 2015, p.120)

Ela parece incomodar-se com os assuntos abordados, mas o receio de ouvi-los pode significar o medo do desconforto frente à sociedade em que vive, posto que as suas inclinações indômitas são inconscientes. Embora busque esquivar-se dos ideais de Bernard, o verde em suas roupas representa o despertar de sua consciência, como o florescer da primavera. Lenina parece estar em busca de algo mais humano e verdadeiro do que a artificialidade do mundo em que vive. Conforme Chevalier e Gheerbrant, o verde carrega esse simbolismo:

é uma cor tranquilizadora, refrescante, humana. A cada primavera, depois do inverno provar ao homem de sua solidão e sua precariedade, desnudando e gelando a terra que ele habita, esta se reveste de um novo manto verde que traz de volta a esperança e ao mesmo tempo volta a ser nutriz. (CHEVALIER; GHEERBRANT, 2009, p. 939).

$\mathrm{Na}$ interpretação dicotômica proposta por Heller (2013), o verde representa o natural, a recusa de um mundo dominado pela tecnologia, enquanto o violeta é a cor mais rara e artificial da natureza. Em suas falas, Lenina afirma adorar tudo o que é moderno e tecnológico, seguindo o pensamento predominante. No entanto, a curiosidade em conhecer uma

8 Segundo Chevalier e Gheerbrant (2009) a goela simboliza a passagem ao subterrâneo, como se a luz fosse devorada; uma passagem para a escuridão, da vida para a morte. O simbolismo também está ligado à goela de um monstro, verde por fora e vermelho por dentro, sendo o violeta justamente derivado desta cor interior. 
Reserva Selvagem e posterior interesse por um homem nascido e criado nesse local demonstram a existência de uma busca pela veracidade do que é natural. Ainda segundo Heller (2013), o verde é a cor da esperança e da liberdade. Essa ideia vai ao encontro da colocação de Chevalier e Gheerbrant (2009), do violeta como símbolo da passagem para a escuridão. A utilização do violeta, por Lenina, representaria o apagamento da luz do espírito da personagem, resultando na total submissão psicológica, como se sucumbisse, por completo, às regras do Estado Mundial. Enquanto isso, a opção pelo vestuário verde representa a busca pela liberdade de ter luz própria. Externamente, Lenina parece estar totalmente adaptada ao meio e aprovar o modelo sócio-cultural dessa sociedade. Internamente, no entanto, ela busca uma alternativa. A existência do conflito de identidade é elucidada por Kathryn Woodward:

A complexidade da vida moderna exige que assumamos diferentes identidades, mas essas diferentes identidades podem estar em conflito. Podemos viver, em nossas vidas pessoais, tensões entre nossas diferentes identidades quando aquilo que é exigido por uma identidade interfere com as exigências de uma outra (WOODWARD, 2000, p.32).

$\mathrm{Na}$ obra de Huxley, as identidades coletivas costumam ser mais marcante e definidas do que as individuais. Lenina e os demais indivíduos "civilizados" definem-se como uma sociedade avançada, que representa a modernidade e tudo o que é novo, posto que são regidos pela tecnologia. Em oposição, classificam aqueles que vivem fora desse modelo social como selvagens, ou seja, que não evoluíram, que permaneceram fora do processo civilizatório. Essa distinção é importante para estabelecer a identidade coletiva do Estado Mundial. Segundo Woodward, "a identidade é relacional, marcada pela diferença e pela exclusão" (2000, p. 8). Ou seja, para existir, ela necessita de outra, diferente, pois é isso que gera a distinção e a demarcação de sua própria identidade. A autora complementa: "Essa marcação da diferença ocorre tanto por meio de sistemas simbólicos de representação, quanto por meio de formas de exclusão social. A identidade, pois, não é o oposto da diferença: a identidade depende da diferença" (WOODWARD, 2000, p. 39-40).

Quando Lenina viaja até a Reserva Selvagem, depara-se, pela primeira vez, com a dessemelhança. A cultura, os costumes e as condições de vida do local geram estranheza e espanto na personagem, devido às diferenças culturais entre as duas sociedades. No entanto, quando ela conhece John e sente-se interessada por ele, a troca de conversas e relatos desencadeia um processo de hibridismo entre ambos. De acordo com Peter Burke, quando há um espaço de troca cultural, há determinado grau de entendimento, ainda que as visões de mundo desses indivíduos com identidades diversas permaneçam distantes.

Sempre que ocorre uma troca cultural, podemos falar metaforicamente de uma zona de comércio, como faz o historiador da ciência Peter Galisson em um estudo do que ele chama de subcultura da física do século XX, no qual descreve estas zonas como espaços onde dois grupos dessemelhantes podem encontrar uma base 
para o entendimento mútuo, trocar itens ao mesmo tempo em que discordam sobre a importância do que é trocado (BURKE, 2003, p. 39).

No caso de Admirável mundo novo, não há uma troca de itens, mas, sim, de ideias. E o que se percebe ser consideravelmente dissonante entre as duas culturas em questão são os pensamentos sobre moral, valores, liberdade e felicidade.

Apesar das diferenças, ou, justamente, por conta delas, a identidade "fabricada", de Lenina, que já mostrava pequenos indícios de estar fora do padrão geral, sofre mais uma interferência, que provoca instabilidade. Como afere Burke (2003), a hibridização baseia-se na noção de que encontros culturais levam a uma miscigenação, seja de maneira consciente ou inconsciente. Esse contato gera efeitos e as culturas não permanecem insensíveis a isso. Ao mesmo tempo, uma cultura não vai dominar por completo a outra. O que vai ocorrer é uma mistura, uma troca entre os indivíduos que mantêm essa relação.

No entanto, a hibridização parece ser assustadora para Lenina que é duplamente abalada, tanto pelo confrontamento com uma identidade tão distinta, quanto pela atração que sente por John, que não é correspondida da maneira esperada por ela. Ao contrário da cultura da mulher, em que não existem sentimentos afetivos nos relacionamentos, os costumes do Selvagem determinam que não é aceitável envolver-se de forma íntima e repentina com uma desconhecida. Assim, o desejo de Lenina não é imediatamente saciado, causando grande desconforto para uma pessoa que desconhecia rejeições:

Lenina sentiu, de súbito, todas as sensações normalmente experimentadas no início de um tratamento Sucedâneo de Paixão Violenta - uma sensação de vácuo atroz, uma apreensão ofegante, náuseas. Parecia-lhe que o coração deixava de pulsar (HUXLEY, 2014, p. 211).

Após Lenina e Bernard, em companhia de John, retornarem da Reserva Selvagem, a jovem tenta, em diversos momentos, aproximar-se do rapaz sempre sem sucesso. Lenina, cada vez mais tomada por um sentimento desconhecido, decide, então, tomar uma atitude desesperada: procura John, incisivamente, disposta a entregar-se. Novamente, ela demonstra seus sentimentos e modificações identitárias por meio da cor de sua roupa, indo ao encontro do Selvagem trajando vestes brancas: "Diante dele, vestida com um traje branco de marinheiro, de cetim de acetato, com um gorro branco inclinado audaciosamente sobre a orelha esquerda, estava Lenina" (HUXLEY, 2014, p. 228).

Para Heller (2013), o branco pode simbolizar a inocência e a castidade, como representadas pela tradição do vestido de noiva. Entretanto, o uso do branco pode ter outros significados, posto que Lenina utiliza a coloração especialmente para seduzir o rapaz. É possível compreender a coloração como a ideia de uma oferenda, visto que ela está disposta a renunciar ao seu sistema cultural em razão de um amor proibido. Como exemplifica Heller, nas história bíblicas, são oferecidos, principalmente, itens brancos para expiar as culpas humanas: "os supersticiosos fazem oferenda dos 'três presentes brancos', em geral, farinha, leite e ovos” (2013, p. 306). A ideia do branco como a cor representativa de oferendas é cor- 
roborada por Chevalier e Gheerbrant, que afirmar ser comum remeter ao cordeiro branco - animal que pode ser oferecido em sacrifício:

Em todas as etapas do desenvolvimento da civilização mediterrânea [...] o cordeiro primogênito, aquele que se denomina, hoje em dia, de cordeiro-do-São-João, surge, em sua brancura imaculada e gloriosa, como uma cratofania primaveril; encarna o triunfo da renovação, a vitória, sempre a renovar-se, da vida sobre a morte (CHEVALIER; GHEERBRANT, 2009, p. 287).

Nas circunstâncias da obra, o sacrifício de Lenina não se refere à morte, mas a uma grande e perigosa decisão: ela ousa comprometer a estabilidade de sua felicidade manufaturada para se arriscar em um relacionamento com uma pessoa tão diferente. Assim, o branco pode ser interpretado como transformação, considerando as alterações provocadas no senso identitário da jovem, ao experimentar sentimentos como a paixão. Consoante Chevalier e Gheerbrant (2009), o branco também é cor de transição, comumente utilizada em rituais de passagem. Para Lenina, pode representar o renascimento de sua identidade, que deixou de ser "pura" para se tornar híbrida.

Apesar da intenção de Lenina de conquistar o Selvagem, o desejo não é consumado. Quando John percebe o objetivo da Beta, é invadido por um sentimento de indignação. O episódio abala emocionalmente a personagem, que tinha sentimentos verdadeiros por John e, como pode ser interpretado pelos trajes brancos, estava disposta a sacrificar-se para ter um relacionamento diferente dos outros que havia experienciado até então. A ira e a rejeição, por parte de John, fazem com que Lenina resigne-se e desista do Selvagem.

Ao final da obra, quando Lenina vai até a montanha para visitar o Selvagem, é possível observar a hibridização da Beta: "com um calção de belbutina verde, uma blusa branca e, na cabeça, um boné de jóquei, apareceu uma moça. À visão da jovem, o Selvagem estremeceu, recuou, empalideceu" (HUXLEY, 2014, p. 304). Desse modo, percebe-se que Lenina continua passando por transformações. Consoante Hall (2000, p. 108), as identidades nunca são singulares. Elas são "multiplamente construídas ao longo de discursos, práticas e posições que podem se cruzar ou ser antagônicas. As identidades estão sujeitas a uma historicização radical, estando constantemente em processo de mudança e transformação." Embora tenha retornado à aparente segurança do totalitarismo do Estado Mundial, Lenina tende a continuar sofrendo modificações, em um processo irreversível e, para ela, aparentemente imperceptível.

\section{CONSIDERAÇÕES FINAIS}

A normatização das identidades é o tema central da obra Admirável Mundo Novo. Além do controle genético, processos de condicionamento aplicados desde a infância auxiliam na fabricação de identidades, parecendo funcionar para a maioria dos indivíduos. No entanto, Huxley apresenta a ideia de que um controle total não pode ser alcançado, visto que alguns personagens demonstram sinais de autenticidade e de individualidade, ainda 
que de maneira superficial. Esse é o caso de Lenina, cuja trajetória e cores de vestimentas foram objeto de análise neste artigo. Apesar de ela, em muitas ocasiões, seguir as normas vigentes e mostrar-se coerente ao condicionamento a que foi exposta, é possível observar, ao longo da obra, que sua identidade possui elementos genuínos. Exemplo disso é o verde predominante em suas roupas, desarmônico em relação aos demais membros de sua casta, que trajam peças majoritariamente violetas. A interpretação dessas cores pode explicar a preferência de Lenina, posto que a juventude e a liberdade, representados pelo verde, são perceptíveis nas características da personagem. Conforme Farina (1990, p. 101) “[...] a cor é uma realidade sensorial à qual não podemos fugir. Além de atuarem sobre a emotividade humana, as cores produzem uma sensação de movimento, uma dinâmica envolvente e compulsiva."

A tendência heterogênea da identidade de Lenina fica ainda mais evidente quando ela tem contato com John, membro de uma cultura alternativa, e que vive no ambiente externo às fronteiras de "civilização". A partir desse encontro, inicia-se o processo de hibridismo cultural, em que, conforme Cuche (1999) as trocas sociais são elementos centrais na característica maleável das identidades, que são constantemente reconstituídas.

Apaixonada por John, Lenina utiliza vestimentas brancas para expressar a sua entrega. Enquanto, para ela, a coloração representa o símbolo da oferenda, ele parece interpretar como a cor da imaculada virgindade, que deve ser conquistada e merecida. Por fim, após a rejeição de John, que passa a perceber Lenina de forma negativa, a jovem retorna às vestes esverdeadas. No entanto, sua identidade, uma vez híbrida, jamais voltará a ser a mesma, como afirma Cuche (1999, p. 192): "O caráter flutuante que se presta a diversas interpretações ou manipulações é característico da identidade. É isto que dificulta a definição desta identidade".

Em suma, a análise dessas particularidades da obra permite constatar a força simbólica e representativa das cores, que podem estar intimamente relacionadas com a representação das identidades dos personagens. Por meio de suas vestimentas, Lenina caracteriza, inconscientemente, a intenção de se libertar das amarras e buscar uma individualidade em relação a outros. No romance de Aldous Huxley, mesmo com fronteiras hermeticamente fechadas e com a utilização de diferentes técnicas de condicionamento, nota-se que a capacidade de adaptação e de maleabilidade das identidades sociais pode sobrepor-se à tentativa de controle absoluto. Diante disso, percebe-se que a previsível imprevisibilidade do ser humano não pode ser, completamente, controlada. 


\section{REFERÊNCIAS}

ADORNO, Theodor. Aldous Huxley e a utopia. In: Prismas: crítica cultural e sociedade. São Paulo: Ática, 2001

BOURDIEU, Pierre. O poder simbólico. São Paulo: Bertrand Brasil, 1989.

BURKE, Peter. Hibridismo cultural. São Leopoldo: Editora Unisinos, 2003.

CHEVALIER, Jean; GHEERBRANT, Alain. Dicionário de símbolos: mitos, sonhos, costumes, gestos, formas, figuras, cores, números. Rio de Janeiro: José Olympio, 2017.

CUCHE, Denys. A noção de cultura nas ciências sociais. Bauru, EDUSC, 1999.

FARINA, Modesto. Psicodinâmica das cores em comunicação. São Paulo: Edgar Blücher, 1990.

HALL, Stuart. A identidade cultural na pós-modernidade. Rio de Janeiro: Lamparina, 2015.

. Quem precisa de identidade? In: SILVA, Tomaz Tadeu da (org.). Identidade e diferença: a perspectiva dos estudos culturais. Petrópolis: Vozes, 2000.

HELLER, Eva. A psicologia das cores: como as cores afetam a emoção e a razão. São Paulo: Gustavo Gili, 2013.

HILÁRIO, Leomir Cardoso. Teoria crítica e literatura: a distopia como ferramenta de análise radical da modernidade. Anuário de literatura, Florianópolis, v.18, n. 2, p. 201-215, 2013.

SHAKESPEARE, William. A tempestade. São Paulo: 1996. Melhoramentos.

WOODWARD, Kathryn. Identidade e diferença: uma introdução teórica e conceitual. In: SILVA, Tomaz Tadeu da (org.). Identidade e diferença: a perspectiva dos estudos culturais. Petrópolis: Vozes, 2000. 